\title{
Services for women's sexual and reproductive health in India: an analysis of treatment-seeking for symptoms of reproductive tract infections in a nationally representative survey
}

\author{
Shikha Bhasin ${ }^{\dagger}$, Ankita Shukla ${ }^{\dagger}$ and Sapna Desai ${ }^{*}$ (i)
}

\begin{abstract}
Background: Women's health policy in India has had a longstanding focus on maternal health and family planning. Recent policy highlights the importance of expanding women's access to a broader range of sexual and reproductive health services. However, there has been very limited analysis of national survey data to examine the current status of treatment utilisation, variation across states and progress over time.

Methods: This paper examines women's treatment patterns for reproductive tract infections in India, based on data collected in the National Family Health Survey, a cross-sectional, nationally representative household survey conducted between 2015-16. The survey covered 699,686 women between the ages 15 and 49, of which 91,818 ever sexually active women responded to questions related to symptoms of reproductive tract infections. We estimate prevalence of reported symptoms and treatment-seeking, describe regional variation and utilise multivariable logistic regression to identify factors associated with women's treatment-seeking patterns.

Results: Thirty-nine percent of women who reported symptoms of reproductive tract infections sought any advice or treatment. Women's reported treatment-seeking in India has not changed since the last national survey a decade earlier. Reported symptoms and treatment-seeking varied widely across India, ranging from 64\% in Punjab to 8\% in Nagaland, with no clear regional pattern that emerged. Seventeen percent of symptomatic women sought services in the public sector, an improvement from $11 \%$ in 2005-06. Twenty-two percent utilised the private sector, with wide variation by states. National-level multivariable logistic regression indicated that treatment-seeking was associated with age, higher education, higher household wealth and having been employed in the past year. Women in the $25-35$ age group had higher odds (aOR1.27; 95\% Cl: 1.10,1.50) of seeking treatment compared to both younger (15-19years) and older (35 years and above) women, along with women with more than eight years of schooling (aOR: 1.23; 95\% Cl: 1.05,1.44) and from richer wealth quintiles (aOR: 1.53; 95\% Cl: 1.35,1.83).

(Continued on next page)
\end{abstract}

\footnotetext{
* Correspondence: sdesai@popcouncil.org

'Shikha Bhasin and Ankita Shukla contributed equally to this work.

Population Council, Zone 5A, Habitat Centre, New Delhi, India
}

C C The Author(s). 2020 Open Access This article is licensed under a Creative Commons Attribution 4.0 International License, which permits use, sharing, adaptation, distribution and reproduction in any medium or format, as long as you give appropriate credit to the original author(s) and the source, provide a link to the Creative Commons licence, and indicate if changes were made. The images or other third party material in this article are included in the article's Creative Commons licence, unless indicated otherwise in a credit line to the material. If material is not included in the article's Creative Commons licence and your intended use is not permitted by statutory regulation or exceeds the permitted use, you will need to obtain permission directly from the copyright holder. To view a copy of this licence, visit http://creativecommons.org/licenses/by/4.0/ The Creative Commons Public Domain Dedication waiver (http://creativecommons.org/publicdomain/zero/1.0/) applies to the data made available in this article, unless otherwise stated in a credit line to the data. 
(Continued from previous page)

Conclusion: Women's use of services for reproductive tract infections remains a challenge in most parts of India.

Our findings highlight the need to address barriers to seeking care and to improve measurement of gynaecological ailments in national surveys.

Keywords: Reproductive tract infections; gynaecological morbidity, Treatment seeking, India, women's health

\section{Background}

Expanding priorities for women's health beyond family planning and maternal health has been an important achievement of global policy advocacy in the past twentyfive years $[1,2]$. Policies and international commitments have progressed from population control to seeking to ensure sexual and reproductive health and rights within Universal Health Coverage (UHC) - albeit with challenges in achieving a comprehensive women's health approach through the life cycle $[1,3]$. In India, policies since the 2000s and the recent National Health Policy (2017) have supported the expansion of women's health beyond maternal health to include treatment for reproductive tract infections (RTIs), cervical cancer screening and noncommunicable diseases [4]. Most recently, the 2018 India Strategy for Women, Adolescents and Child Health (IWACH) builds on these policies to articulate a life-course approach to women's health that encompasses prevention, promotion, treatment and social determinants of health [5]. As India advances on the path towards UHC, it is critical to reflect on whether shifts in policy priorities to expand women's health beyond maternal health and family planning have translated into increased service utilisation by women [4].

Population-based surveys in India provide an opportunity to examine progress over time and across states for some indicators of women's health. The country's major health surveys, the National Family Health Survey (NFHS) and sub-national District Level Household Survey (DLHS), focus primarily on maternal and child health and family planning, with more recent inclusion of intimate partner violence and risk factors for non-communicable disease [6]. The DLHS collects data on gynaecological morbidity, specifically symptoms of menstrual disorders and reproductive tract infections (RTIs), and the NFHS only collects evidence on the latter. While tracking women's vulnerability to cardiovascular disease and cancer is a recent initiative, treatment for RTIs has been a longstanding measurement and policy priority.

Reproductive tract infections, which commonly may be undiagnosed or untreated, can lead to complications such as pelvic inflammatory disease, chronic pelvic pain and infertility, adverse pregnancy outcomes, as well as increased risk of HIV transmission [7]. National surveys in India define symptoms of RTIs as abnormal genital discharge, ulcers, sores or other ailments due to sexual contact, thus focussing on a subset of sexually transmitted infections (STIs). They do not include other symptoms of infections, such as burning urination or pelvic pain. In 1998-9, the NFHS-2 estimated that 35\% of ever sexually active women who reported symptoms of RTIs had sought advice or treatment [8]. The following decade, the DLHS3 (2008-9), a sub-nationally representative survey conducted amongst ever-married women, reported that $40 \%$ of symptomatic women sought treatment for RTIs and $12 \%$ reported menstrual disorders [9].

A systematic review of seventeen community-based studies on treatment for RTIs and STIs in India, across rural and urban populations in most states except Kerala and the North East, estimated that between 16 to $55 \%$ of women with symptoms sought treatment [10]. Community-based research has also highlighted variation in self-reported symptoms and treatment across geographic context and by women's own perceptions of morbidity. Different methodological approaches, such as studies that use self-reported symptoms compared to those that employ clinical diagnosis, render comparison difficult across settings [10-14]. Nonetheless, community-based research has consistently identified barriers to treatment seeking for RTIs, and the critical importance of expanding women's access to appropriate, accessible treatment [14-18].

Since the last round of the NFHS in 2005-6, India's National Health Mission has introduced a range of measures to improve women's utilisation of maternal and child health services. The most recent NFHS round (2015-16) provides an opportunity to review women's treatment patterns for RTIs, in light of progress in maternal health and recent policy commitments to expand SRH services. This paper utilises nationally representative data to examine: (i) the current status of women's treatment-seeking for symptoms of RTIs; (ii) state-level variation; and (iii) correlates of seeking treatment. We also identify gaps in the measurement of women's gynaecological morbidity in national surveys to improve monitoring of, and action for, women's health in India.

\section{Methods}

The study draws from the fourth round of the National Family Health Survey (NFHS-4), a nationally representative, cross-sectional, household sample survey conducted in all states and union territories of India [19]. The 
NFHS provides estimates on population, health and nutrition as reported by adults aged 15-49. The NFHS-4 survey adopted a stratified two-stage sampling design, utilising the 2011 census as the sampling frame for the selection of primary sampling units (PSUs). PSUs, villages in rural areas and census enumeration blocks in urban areas, were selected using probability proportional to size sampling. Households were selected through systematic random selection of households within each PSU [20].

The Woman's Questionnaire collected information from women aged 15-49 on: reproductive and sexual health including contraception, maternal health and gender-based violence; empowerment-related issues such as decision-making and mobility; and non-communicable diseases. State-level modules included three questions about RTIs for women who reported being sexually active, irrespective of their marital status: experience of ailments due to sexual contact; bad-smelling abnormal genital discharge; and the presence of genital sores or ulcers, all within the twelve- month period before the survey.

Women who reported at least one symptom were asked a follow-up question about whether they sought treatment/advice and a multiple response question on the facilities where treatment was sought. Two binary outcome variables were constructed based on whether women reported at least one of the symptoms of RTIs and whether they sought any treatment/advice. Data regarding treatment/advice for reported symptoms were collected according to type of facility visited by the respondent, categorized as public, private, or others. Public included government hospital, government AYUSH doctor, government health centre, family planning clinic, mobile clinic, govt. fieldworker, school-based clinic or other public facilities. Private included private hospital/clinic/doctor, private AYUSH doctor, pharmacy, private mobile clinic, private health worker and other private facilities. Other facilities included non-government organisations, home treatment, correctional facility and other facilities.

We identified independent variables for crude analyses based on a review of the literature and availability of data in the NFHS-4. These included: woman's age (15$25,25-35$ and more than 35 years); years of schooling (none, 1-8 years and more than 8 years); religion (Hindu, Muslim, and others); caste (scheduled tribe/caste (ST/ $\mathrm{SC})$, other backward caste (OBC) and others); residence (urban and rural); household wealth index (a composite score based on household assets categorized into three categories: poor, middle and rich); marital status (unmarried and married); engaged in work in the last year (yes/no); if women considered distance to a health facility a problem (yes/no); freedom of mobility (no mobility at all and mobility for at least one of the following-to go market, health facility or outside village); role in decision-making (none at all or for at least one of: health care, large household purchases and daily needs); and exposure to intimate partner violence in the home (yes/ no).

The survey's state modules collected information on symptoms of RTIs from 91,818 women who reported being sexually active. We estimated prevalence and treatment-seeking based on these self-reported responses, presented with 95\% confidence intervals and geographic distribution. We calculated unadjusted odds ratios to estimate associations for variables identified from the literature. The multivariable regression model to estimate adjusted odds ratios included variables which had evidence of association $(p<0.05)$ in the crude analyses. Analyses were conducted in Stata 13 using the svy command to adjust for survey design and sampling weights.

\section{Results}

Background characteristics of the sub-sample of women who reported being sexually active are presented in Table 1 . Thirty four percent of women had no education and $70 \%$ were from rural areas. The large majority were ever married (94\%). Over 1 in 4 (28\%) reported ever experiencing any form of intimate partner violence.

An estimated $11.3 \%$ of 91,818 ever sexually active women aged 15-49 reported symptoms of RTIs. Of symptomatic women, $39.2 \%$ (95\% CI: $37.8,40.7$ ) sought any treatment/advice in 2015-16 (Table 2). Of those who reported symptoms (2015-16), 17.0\% utilized public services, $22.4 \%$ private services, and $2.2 \%$ sought treatment in other facilities which included home treatment, $\mathrm{NGO}$ /trust providers and community-based services. The overall proportion of women who sought treatment has not changed since the NFHS-3 in 2005-6 (40.4\%). The proportion of women who sought care in public facilities increased from $11.4 \%$ (CI: 10.5, 12.3) in NFHS3 to $17.0 \%$ (CI: 15.9,18.2) in NFHS-4 (Table 2).

The proportion of women who reported symptoms and seeking treatment varied considerably across India (Fig. 1). Relatively higher proportions were reported in Meghalaya (26.2\%); Haryana (23.4\%); Jammu \& Kashmir (23.1\%), and Mizoram (11.2\%). The distribution of seeking treatment, however, did not follow a similar pattern. Treatment-seeking was as low as $7.6 \%$ in Nagaland and $19.3 \%$ in Assam. Women reported higher levels of seeking treatment in the following states: Punjab (63.9\%), Kerala (63.4\%), Himachal Pradesh (48.2\%), Telangana (47.3\%) and Haryana (44.6\%).

Use of public and private services also varied considerably between states (Table 3). A high proportion of symptomatic women accessed public facilities in states such as Karnataka (40.9\%), Sikkim (33.4\%), Himachal Pradesh (32.9\%), Kerala (32.3\%) and Jammu and Kashmir (27.1\%). This proportion was considerably lower in 
Table 1 Background characteristics of adult women who reported being sexually active, NFHS-4

\begin{tabular}{|c|c|c|}
\hline & \multicolumn{2}{|c|}{ NFHS $4(N=91,818)$} \\
\hline & $\mathrm{n}^{*}$ & $\%$ \\
\hline \multicolumn{3}{|l|}{ Age group } \\
\hline $15-25$ & 21,038 & 22.9 \\
\hline $25-35$ & 34,531 & 37.6 \\
\hline $35 \&$ above & 36,249 & 39.5 \\
\hline \multicolumn{3}{|c|}{ Years of schooling } \\
\hline No education & 30,939 & 33.7 \\
\hline $1-8$ years & 28,168 & 30.7 \\
\hline $8+$ years & 32,711 & 35.6 \\
\hline \multicolumn{3}{|l|}{ Residence } \\
\hline Urban & 27,103 & 29.5 \\
\hline Rural & 64,715 & 70.5 \\
\hline \multicolumn{3}{|l|}{ Wealth Index } \\
\hline Poor & 36,020 & 39.2 \\
\hline Middle & 19,389 & 21.1 \\
\hline Rich & 36,409 & 39.7 \\
\hline \multicolumn{3}{|l|}{ Religion } \\
\hline Muslim & 12,581 & 13.7 \\
\hline Hindu & 69,156 & 75.3 \\
\hline Others & 10,081 & 11.0 \\
\hline \multicolumn{3}{|l|}{ Caste } \\
\hline $\mathrm{ST} / \mathrm{SC}$ & 32,365 & 35.2 \\
\hline $\mathrm{OBC}$ & 36,113 & 39.3 \\
\hline Others & 23,340 & 25.4 \\
\hline \multicolumn{3}{|l|}{ Marital Status } \\
\hline Unmarried & 5909 & 6.4 \\
\hline Ever Married & 85,909 & 93.6 \\
\hline \multicolumn{3}{|l|}{ Occupation } \\
\hline Not working & 62,107 & 68.4 \\
\hline Working & 28,656 & 31.6 \\
\hline \multicolumn{3}{|c|}{ Distance to health facility } \\
\hline No problem & 32,874 & 35.8 \\
\hline Problem & 58,944 & 64.2 \\
\hline \multicolumn{3}{|c|}{ Role in decision making } \\
\hline No & 30,852 & 35.9 \\
\hline Yes & 55,057 & 64.1 \\
\hline \multicolumn{3}{|c|}{ Freedom of Mobility } \\
\hline No & 51,856 & 56.5 \\
\hline Yes & 39,962 & 43.5 \\
\hline \multicolumn{3}{|c|}{ Ever experienced violence } \\
\hline No & 47,050 & 72.0 \\
\hline Yes & 18,302 & 28.0 \\
\hline
\end{tabular}

Jharkhand (2.6\%), Nagaland (3.9\%), Assam (6.0\%) and Bihar (8.0\%). Between NFHS rounds 3 and 4, women's utilisation of private facilities decreased by $1.7 \%$ points and increased for public facilities by $5.6 \%$ points at the national level, with variation by states (Fig. 2). Increases in use of the public sector were relatively higher in Karnataka (17.3\%), Sikkim (12.6\%), Meghalaya (11.9\%) and Kerala (10.1\%), while private utilisation increased in Punjab (8.7\%), Rajasthan (6.9\%) and Meghalaya (6.8\%).

Table 4 reports both prevalence and treatment-seeking patterns from NFHS-4. Estimates of prevalence and treatment-seeking were lowest amongst younger women. Women with no education and lower economic status reported symptoms in higher proportions but reported relatively lower treatment-seeking. Women who reported distance as a barrier in seeking health services also reported lower treatment-seeking. A higher proportion of women who had ever experienced violence reported symptoms compared to women who did not report exposure to violence, but treatment-seeking was similar in both groups.

Unadjusted odds ratios (Table 5) suggested that age, years of schooling, urban/rural residence, current employment, wealth, and caste were associated with women's treatmentseeking. There was no evidence that women's marital status, distance from a health facility, decision-making power, freedom of mobility and exposure to intimate partner violence were associated with seeking treatment. Adjusted analyses (Table 5) indicated evidence for associations of age, education, wealth, caste, and work status with seeking treatment amongst adult women. Women in the age group 25-35 years had higher odds of seeking treatment (aOR $1.27,95 \%$ CI: $1.09,1.47)$ as compared to both younger (1525 years) and older ( 35 years and above) women. Higher education was associated with reporting seeking treatment: those with 1-8 years of schooling had higher adjusted odds (aOR1.39, 95\% CI: 1.21, 1.60), compared to women who had never been to school. The odds of seeking treatment increased with increasing wealth terciles, up to 1.53 (95\% CI: $1.30,1.80)$ in the highest wealth index. There was strong evidence that women who had engaged in work in the last year reported higher odds of seeking treatment/advice (aOR 1.33, 95\% CI: 1.17, 1.51).

\section{Discussion}

This paper presents findings on women's treatment seeking for RTIs, which to our knowledge is only the fourth published analysis of large-scale survey data on this issue in India in the past thirty years [21-23]. Our analysis of women's utilisation of services, across states and over time, suggests that utilisation of services for gynaecological morbidity remains a challenge in most parts of India. Less than $40 \%$ of women in India who reported symptoms of RTIs reported seeking care- no improvement since the NFHS-3 ten years earlier. 
Table 2 Proportion of women who reported symptoms of a reproductive tract infection ${ }^{\text {a }}$ and sought treatment, NFHS-3 and NFHS-4

\begin{tabular}{|c|c|c|c|c|}
\hline & \multicolumn{2}{|c|}{ NFHS 3} & \multicolumn{2}{|c|}{ NFHS 4} \\
\hline & $\%$ & $95 \% \mathrm{Cl}$ & $\%$ & $95 \% \mathrm{Cl}$ \\
\hline Reported symptoms & 11.2 & $(10.7,11.8)$ & 11.3 & $(10.9,11.7)$ \\
\hline Sought treatment (of symptomatic women) & 40.4 & $(38.9,41.8)$ & 39.2 & $(37.8,40.7)$ \\
\hline \multicolumn{5}{|l|}{ Type of facility visited } \\
\hline Public facility & 11.4 & $(10.5,12.3)$ & 17.0 & $(15.9,18.2)$ \\
\hline Private facility & 24.1 & $(22.9,25.4)$ & 22.4 & $(21.2,23.7)$ \\
\hline Others & 7.4 & $(6.6,8.1)$ & 2.2 & $(1.8,2.6)$ \\
\hline
\end{tabular}

${ }^{a}$ Reported symptoms of RTI include if the women experienced any one of the following: any infection due to sexual contact, genital sore/ulcer; or abnormal genital discharge

Neighbouring countries such as Nepal and Bangladesh report higher proportions of women who sought treatment for similar symptoms: 48 and 60\%, respectively $[24,25]$. Our analysis, similar to previous NFHS and DLHS rounds, indicated wide variation in treatment utilisation across Indian states, ranging from $64 \%$ in Punjab to $8 \%$ in Nagaland. Given that health is a state subject in India, differences in state-level health systems likely contribute to this variation. We could not identify any regional patterns or variation consistent with national rankings of state health system performance [26]. The use of public services increased slightly in the past ten years, with declines in utilisation of private facilities in some states. In Punjab, Rajasthan, Uttar Pradesh and Kerala, utilisation increased in both sectors.

\section{Barriers to treatment}

Our analysis indicates that equitable access to services is of concern: women who are younger, have no education, lower economic status and reside in rural areas reported lower levels of seeking care, similar to findings from a range of community-based studies [17, 18, 27]. In addition, a comparative analysis of NFHS-II, NFHS-III and DLHS RCH-I and II found higher treatment-seeking amongst women with a higher standard of living, education level and age [28]. Similarly, an analysis of NFHS-2 (1998-99) indicated that seeking care varied according to location and by socioeconomic and demographic group: wealthier, older, educated women were more likely to seek treatment [21].

Qualitative research has indicated that individual perceptions-such as a well-established notion of a "culture of silence" around gynaecological ailments-and limiteddecision making power prevent treatment-seeking [29-31]. Women's normalisation of symptoms, or fear/ embarrassment as barriers to treatment, point to deeper-rooted sociocultural ideas around gynaecological morbidity [11, 13, 32]. Women may believe that reproductive health problems,
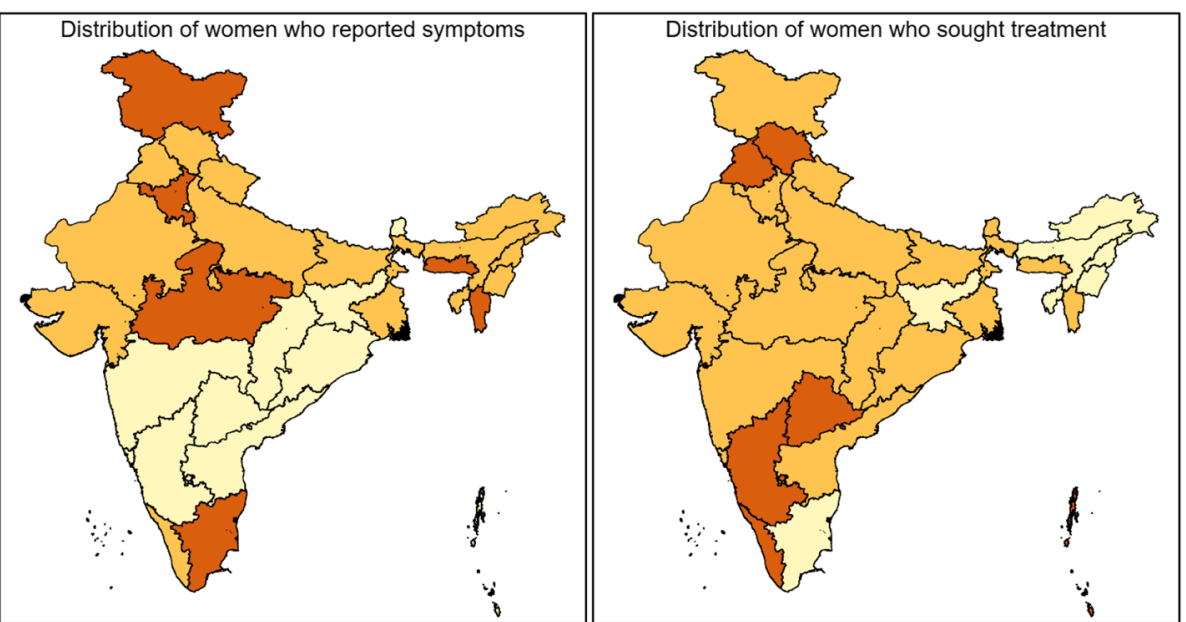

Fig. 1 Distribution of women who reported symptoms and of who sought treatment. The maps depicted in Fig. 1 were made by the authors using an India country shape file and STATA 13 (map not to scale, image of Indian state borders as published in Administrative Atlas of India, Census of India 2011). It was digitized in ArcGIS software to generate a country shape file. Distribution of women who reported symptoms $0-6.9$ 11.0-19.0. Distribution of women who sought treatment $\quad$ 0-29.9 $\quad 30.0-44.9$ _ 45.0-65.0. 
Table 3 Proportion of women who sought treatment, by sector, NFHS-3 and NFHS-4 (\%)

\begin{tabular}{|c|c|c|c|c|c|c|}
\hline & Public & Private & Other & Public & Private & Other \\
\hline & NFHS 3 & & & NFHS 4 & & \\
\hline Nagaland & 5.4 & 15.0 & 0.0 & 3.9 & 3.7 & 0.0 \\
\hline Arunachal Pradesh & 13.1 & 7.5 & 1.8 & 19.6 & 5.1 & 0.1 \\
\hline Sikkim & 20.8 & 8.4 & 0.0 & 33.4 & 7.4 & 0.0 \\
\hline Odisha & 21.9 & 17.6 & 10.2 & 18.1 & 8.5 & 4.1 \\
\hline Karnataka & 23.6 & 36.3 & 1.5 & 40.9 & 10.1 & 0.3 \\
\hline Tamil Nadu & 32.1 & 31.7 & 0.6 & 20.6 & 10.8 & 0.4 \\
\hline Assam & 12.9 & 12.9 & 15.1 & 6.0 & 10.9 & 2.5 \\
\hline Mizoram & 24.0 & 10.7 & 0.7 & 24.3 & 11.0 & 1.3 \\
\hline Tripura & 17.6 & 17.6 & 13.5 & 9.6 & 12.2 & 0.0 \\
\hline Manipur & 18.2 & 24.2 & 2.5 & 15.9 & 13.2 & 3.2 \\
\hline Jammu and Kashmir & 18.4 & 23.1 & 3.5 & 27.1 & 14.5 & 0.9 \\
\hline Himachal Pradesh & 40.0 & 22.9 & 1.6 & 32.9 & 16.8 & 1.1 \\
\hline Rajasthan & 17.6 & 11.3 & 8.2 & 18.8 & 18.2 & 1.8 \\
\hline Meghalaya & 12.5 & 12.1 & 0.0 & 24.3 & 18.9 & 0.0 \\
\hline Jharkhand & 5.3 & 22.9 & 13.6 & 2.6 & 19.1 & 6.2 \\
\hline Madhya Pradesh & 9.6 & 21.2 & 2.8 & 17.8 & 20.6 & 1.6 \\
\hline Goa & 12.1 & 38.0 & 2.2 & 18.1 & 20.6 & 4.8 \\
\hline Delhi & 15.6 & 35.5 & 3.7 & 21.2 & 21.7 & 0.0 \\
\hline Maharashtra & 12.8 & 42.5 & 1.0 & 17.1 & 21.8 & 0.0 \\
\hline Bihar & 3.9 & 26.0 & 7.3 & 8.0 & 23.4 & 1.0 \\
\hline West Bengal & 9.9 & 25.1 & 15.4 & 13.6 & 24.1 & 3.0 \\
\hline Uttarakhand & 20.7 & 21.0 & 5.2 & 20.4 & 24.3 & 0.7 \\
\hline Haryana & 18.7 & 26.8 & 12.9 & 24.4 & 24.6 & 0.5 \\
\hline Chhattisgarh & 16.3 & 18.5 & 4.3 & 11.5 & 24.7 & 1.9 \\
\hline Andhra Pradesh & 16.8 & 26.6 & 1.0 & 10.8 & 26.7 & 3.3 \\
\hline Gujarat & 8.8 & 27.3 & 2.2 & 10.5 & 29.2 & 4.4 \\
\hline Uttar Pradesh & 7.4 & 24.9 & 6.7 & 12.3 & 30.2 & 4.6 \\
\hline Kerala & 22.3 & 29.2 & 8.0 & 32.3 & 32.6 & 0.3 \\
\hline Punjab & 17.1 & 38.8 & 10.8 & 24.6 & 47.4 & 1.4 \\
\hline India & 11.4 & 24.1 & 7.4 & 17.0 & 22.4 & 2.2 \\
\hline
\end{tabular}

Note: proportions are of women who reported symptoms

such as vaginal discharge or pain, are simply "women's fate" and therefore not a condition for which they should seek medical help $[15,33]$. For example, a comparison of treatment-seeking for gynaecological, obstetric and contraceptive morbidity in an urban Delhi community noted that a high proportion (92.9\%) of women sought care for obstetric morbidity, while only $50.8 \%$ of women with gynaecological morbidity sought care [34].

\section{Health system factors}

Community-based research has largely focused on individual or societal barriers to treatment, with relatively less analysis of the availability, acceptability, accessibility, and quality of services in facilities [1, 35]. Available research indicates that women's perceptions of health system barriers include financial constraints [15, 36, 37], poor perceived quality of care, and limited access to appropriate treatment [14-16]. Studies from Gujarat, West Bengal and Tamil Nadu have highlighted the association between cost of care and treatment seeking for gynaecological morbidity [14-16]. Further, vulnerable populations such as migrants/women with migrant husbands and women in the informal economy may face particular challenges in seeking care [38, 39].

Providers' knowledge and attitudes towards women's bodies may also influence women's utilisation of services. For example, a study amongst private providers revealed that most did not perform internal examinations for women with gynaecological ailments [40]. Male healthcare providers in a rural setting indicated that they were unwilling to examine women's "private parts" and instead spoke to escorts, rather than women themselves [13]. Lastly, it is possible that the lack of accessible, acceptable treatment may drive over/mis-use of over-the counter medication without adequate care [32].

Although NFHS-4 did not collect data on use of informal providers, earlier rounds of NFHS suggest they were an important source of care. For example, analyses of NFHS-2 indicated that $14 \%$ of all consultations for gynaecological symptoms were with informal private providers, with higher use in states such as Bihar (28\%), Orissa (25\%), West Bengal (39\%) and Nagaland (35\%). Reported use of informal providers was higher among poorer, lower-caste and uneducated women [21]. More recent community-based studies of women's preferences also indicate women in rural settings prefer traditional healers, informal providers and home remedies for symptoms of RTIs [14, 41].

Finally, it is noteworthy the NFHS survey rounds straddle the introduction of the National Health Mission, a horizontal health systems reforms largely focused on public sector service delivery related to maternal and child health. Although the program has not appeared to have achieved overall gains in treatment-seeking for RTIs, improvements in states such as Karnataka, Kerala and Himachal Pradesh suggest that the public sector may have become a more viable option for utilisation of gynaecological health services in some states.

\section{Strengths and limitations}

The primary strength of this study is the use of nationally representative data that allows comparison of RTI treatment over time and across states. Building on a strong base of existing community-based literature, we examined a range of potential predictors of women's treatment-seeking in a nationally representative dataset. However, our analysis was limited by focussing on national estimates. Predictive factors may be context- 


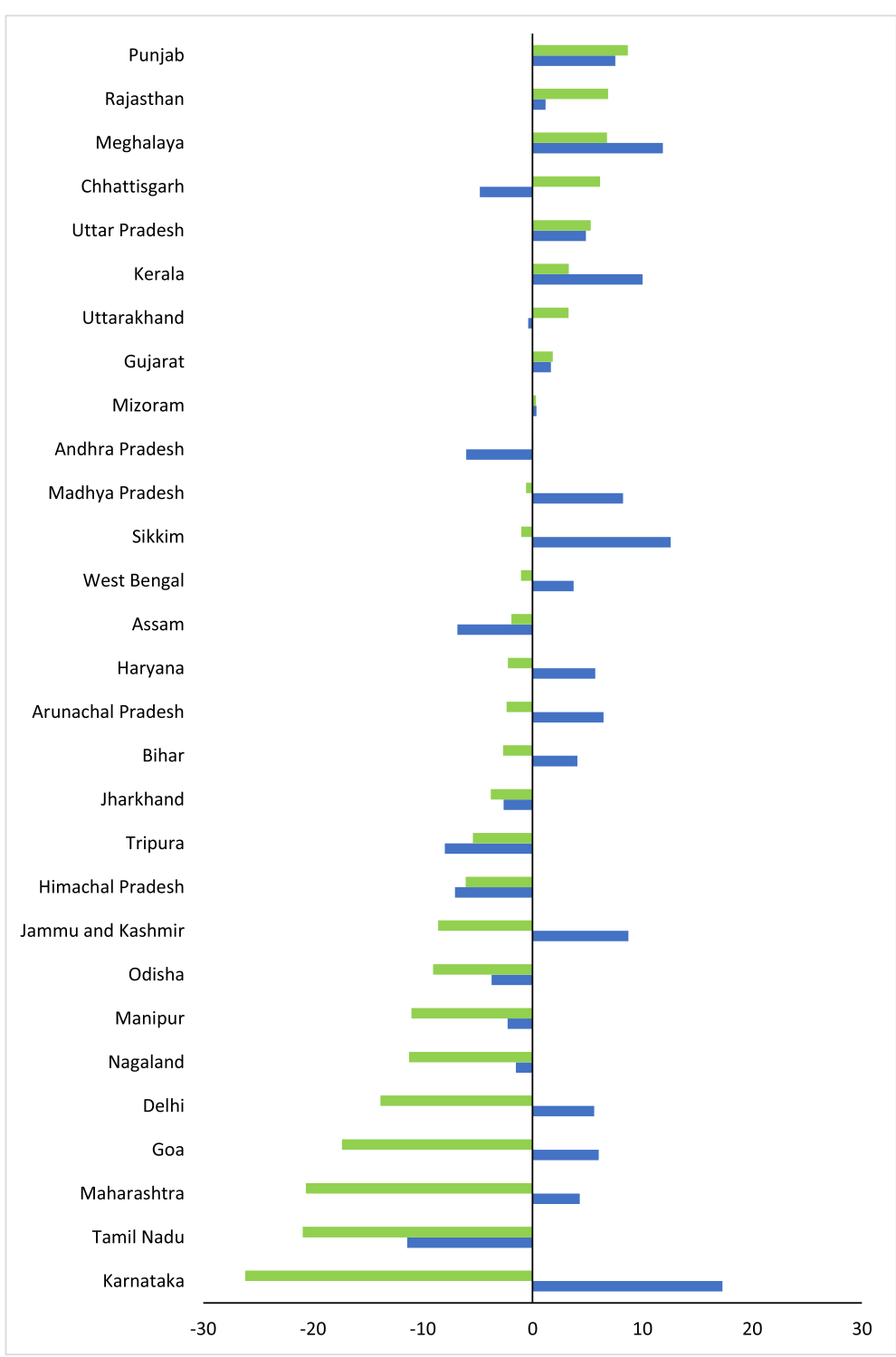

Fig. 2 Changes in proportion of symptomatic women who sought treatment by sector, NFHS-3 to NFHS-4 Fig. 2

Private

Public.

specific, which may explain wide variation between states or lack of associations between women's empowerment indicators and treatment-seeking, for example. The NFHS collects data on women's self-reported symptoms, which could result in underestimates, both due to underreporting and asymptomatic infections [10, 12]. Lastly, our analysis is limited by using a large national survey that examines a range of health issues, which necessarily has a limited number of questions that can incorporate women's perceptions or attitudes that influence treatment-seeking decisions [11, 42, 43].

We identified several areas which can be improved in the module on RTIs within the NFHS. The NFHS collects data on symptoms from women who report a history of sexual activity. This criterion excludes women who are not, or choose not to report, being sexually active; morbidity estimates thus do not include reproductive tract infections amongst women who are not sexually active. The long (12-month) recall period for symptoms may limit the reliability of estimates, with potential variation in the population by severity of symptoms as well as socioeconomic status [44]. Our understanding of factors that influenced treatment behaviour could be improved by data on awareness and availability of services, as well as information on the use of informal providers and the reported cure rate.

\section{Conclusion}

Our findings that only two of five women who experienced symptoms of RTIs sought treatment amplifies the 
Table 4 Proportion of women who reported symptoms and sought treatment, by background characteristics, NFHS-4

\begin{tabular}{|c|c|c|c|}
\hline & $n^{*}$ & Reported symptoms & $\begin{array}{l}\text { Sought treatment of those } \\
\text { who reported symptoms }\end{array}$ \\
\hline \multicolumn{4}{|l|}{ Age group } \\
\hline $15-25$ & 21,038 & $10.7(10.0,11.4)$ & $35.09(32.4,37.9)$ \\
\hline $25-35$ & 34,531 & $12.4(11.8,13.0)$ & $42.22(40.1,44.4)$ \\
\hline $35 \&$ above & 36,249 & $10.5(10.0,11.1)$ & $38.39(36.2,40.5)$ \\
\hline \multicolumn{4}{|c|}{ Years of schooling } \\
\hline No education & 30,939 & $11.8(11.2,12.3)$ & $33.45(31.5,35.5)$ \\
\hline $1-8$ years & 28,168 & $11.7(11.1,12.3)$ & $42.01(39.7,44.4)$ \\
\hline $8+$ years & 32,711 & $10.5(9.9,11.1)$ & $42.3(39.7,44.9)$ \\
\hline \multicolumn{4}{|l|}{ Residence } \\
\hline Urban & 27,103 & $10.5(9.7,11.3)$ & $41.79(38.8,44.9)$ \\
\hline Rural & 64,715 & $11.7(11.2,12.1)$ & $37.99(36.5,39.5)$ \\
\hline \multicolumn{4}{|l|}{ Wealth Index } \\
\hline Poor & 36,020 & $11.9(11.3,12.5)$ & $32.51(30.6,34.5)$ \\
\hline Middle & 19,389 & $11.2(10.5,11.9)$ & $41.05(38.2,44.0)$ \\
\hline Rich & 36,409 & $10.7(10.1,11.3)$ & $44.45(42.1,46.9)$ \\
\hline \multicolumn{4}{|l|}{ Religion } \\
\hline Muslim & 12,581 & $13.0(12.0,14.1)$ & $42.35(38.9,45.9)$ \\
\hline Hindu & 69,156 & $10.9(10.5,11.4)$ & $38.21(36.6,39.8)$ \\
\hline Others & 10,081 & $12.0(10.7,13.4)$ & $44.85(39.5,50.3)$ \\
\hline \multicolumn{4}{|l|}{ Caste } \\
\hline $\mathrm{ST} / \mathrm{SC}$ & 32,365 & 11.7(11.0,12.6) & $36.69(34.4,39.1)$ \\
\hline $\mathrm{OBC}$ & 36,113 & $11.0(10.4,11.5)$ & $38.09(36.1,40.2)$ \\
\hline Others & 23,340 & $11.0(10.2,11.8)$ & $43.94(40.8,47.1)$ \\
\hline \multicolumn{4}{|l|}{ Marital Status } \\
\hline Unmarried & 5909 & $10.4(9.2,11.8)$ & $41.7(36.4,47.2)$ \\
\hline Ever Married & 85,909 & $11.3(11 \cdot 0,11.7)$ & $39.1(37.6,40.6)$ \\
\hline \multicolumn{4}{|l|}{ Occupation } \\
\hline Not working & 62,107 & 10.7(10.2,11.1) & $37.7(36.0,39.5)$ \\
\hline Working & 28,656 & $12.4(11.8,13.1)$ & $41.6(39.5,43.9)$ \\
\hline \multicolumn{4}{|c|}{ Distance to health Facility } \\
\hline No problem & 32,874 & $9.2(8.8,9.7)$ & $42.8(40.2,45.3)$ \\
\hline Problem & 58,944 & $16.0(15.2,16.8)$ & $37.5(35.9,39.2)$ \\
\hline \multicolumn{4}{|c|}{ Role in decision making } \\
\hline No & 51,856 & $9.8(9.2,10.3)$ & $37.5(35.3,39.7)$ \\
\hline Yes & 39,962 & $12.2(11.7,12.7)$ & $40.2(38.2,42.2)$ \\
\hline \multicolumn{4}{|c|}{ Freedom of Mobility } \\
\hline No & 30,852 & $12.8(12.2,13.4)$ & $38.9(37.1,40.7)$ \\
\hline Yes & 55,057 & $10.5(10.0,10.9)$ & $39.7(37.7,41.8)$ \\
\hline \multicolumn{4}{|c|}{ Ever experienced violence } \\
\hline No & 47,050 & $11.7(11.2,12.2)$ & $38.7(36.6,40.8)$ \\
\hline Yes & 18,302 & 10.8(10.2,11.3) & $38.4(36.1,40.8)$ \\
\hline
\end{tabular}

${ }^{*} n$ is the unweighted sample of women who reported being sexually active. Information was missing for occupation in 1,055 cases, for role in decision-making in 5,909 cases and for ever experienced violence in 26,466 cases 
Table 5 Correlates of treatment-seeking amongst women who reported symptoms, NFHS- 4

\begin{tabular}{|c|c|c|c|c|c|c|}
\hline & \multicolumn{3}{|c|}{ Unadjusted } & \multicolumn{3}{|c|}{ Adjusted } \\
\hline & $\mathrm{UOR}$ & $p$-value & $\mathrm{Cl}$ & $\mathrm{aOR}$ & $p$-value & $\mathrm{Cl}$ \\
\hline \multicolumn{7}{|l|}{ Age group } \\
\hline $15-25$ & 1.00 & & & 1.00 & & \\
\hline $25-35$ & 1.32 & 0.00 & $(1.1,1.5)$ & 1.27 & 0.00 & $(1.1,1.5)$ \\
\hline $35+$ & 1.13 & 0.11 & $(1.0,1.3)$ & 1.12 & 0.16 & $(1.0,1.3)$ \\
\hline \multicolumn{7}{|c|}{ Years of schooling } \\
\hline No education & 1.00 & & & 1.00 & & \\
\hline $1-8$ years & 1.45 & 0.00 & $(1.3,1.7)$ & 1.39 & 0.00 & $(1.2,1.6)$ \\
\hline $8+$ years & 1.39 & 0.00 & $(1.2,1.6)$ & 1.23 & 0.01 & $(1.1,1.4)$ \\
\hline \multicolumn{7}{|l|}{ Residence } \\
\hline Urban & 1.00 & & & 1.00 & & \\
\hline Rural & 0.87 & 0.06 & $(0.8,1.0)$ & 1.02 & 0.79 & $(0.9,1.2)$ \\
\hline \multicolumn{7}{|l|}{ Wealth Index } \\
\hline Poor & 1.00 & & & 1.00 & & \\
\hline Middle & 1.46 & 0.00 & $(1.3,1.7)$ & 1.39 & 0.00 & $(1.2,1.6)$ \\
\hline Rich & 1.58 & 0.00 & $(1.4,1.8)$ & 1.53 & 0.00 & $(1.3,1.8)$ \\
\hline \multicolumn{7}{|l|}{ Caste } \\
\hline $\mathrm{ST} / \mathrm{SC}$ & 1.00 & & & 1.00 & & \\
\hline $\mathrm{OBC}$ & 1.07 & 0.32 & $(0.9,1.2)$ & 0.99 & 0.88 & $(0.8,1.1)$ \\
\hline Others & 1.23 & 0.01 & $(1.0,1.3)$ & 1.08 & 0.38 & $(0.9,1.3)$ \\
\hline \multicolumn{7}{|l|}{ Religion } \\
\hline Muslim & 1.00 & & & & & \\
\hline Hindu & 0.86 & 0.08 & $(0.7,1.0)$ & & & \\
\hline Others & 0.82 & 0.26 & $(0.6,1.2)$ & & & \\
\hline \multicolumn{7}{|l|}{ Occupation } \\
\hline Not working & 1.00 & & & 1.00 & & \\
\hline Working & 1.22 & 0.00 & $(1.1,1.4)$ & 1.33 & 0.00 & $(1.2,1.5)$ \\
\hline \multicolumn{7}{|l|}{ Marital Status } \\
\hline Unmarried & 1.00 & & & & & \\
\hline Ever Married & 0.91 & & $(0.71,1.17)$ & & & \\
\hline \multicolumn{7}{|c|}{ Distance to health Facility } \\
\hline No problem & 1.00 & & & 1.00 & & \\
\hline Problem & 0.89 & 0.06 & $(0.8,1.0)$ & & & \\
\hline \multicolumn{7}{|c|}{ Role in decision making } \\
\hline No & 1.00 & & & & & \\
\hline Yes & 1.12 & 0.09 & $(1.0,1.3)$ & & & \\
\hline \multicolumn{7}{|c|}{ Freedom of Mobility } \\
\hline No & 1.00 & & & & & \\
\hline Yes & 1.07 & 0.25 & $(1 \cdot 0,1.2)$ & & & \\
\hline \multicolumn{7}{|c|}{ Ever experienced violence } \\
\hline No & 1.00 & & & & & \\
\hline Yes & 1.04 & 0.56 & $(0.9,1.2)$ & & & \\
\hline
\end{tabular}

need to invest in women's health in India. While institutional deliveries have doubled between NFHS-3 and NFHS-4 [45] treatment-seeking for RTIs has not changed over two decades-despite national and global priority to expand women's health services beyond maternal health and family planning. Having achieved impressive gains in the reduction of maternal mortality, India's policy statements on women's health are an encouraging commitment. Yet from a health systems perspective, effectively providing services for non-maternal gynaecological issues remains a challenge.

Our findings point to three broad implications for action to improve women's utilisation of services for gynaecological morbidity. To start, it will be important to estimate gynaecologic morbidity more comprehensively in the NFHS, for example through inclusion of estimates of the well-established burden of menstrual disorders [46, 47]. Further, treatment for women's gynaecological morbidity should be part of an essential package of services within primary care. Guidelines and training within primary health care and health and wellness centres should ensure inclusion of women's non-maternal, gynaecologic health needs, particularly symptoms of infections and menstrual disorders along with cancer screening. Lastly, it is critical to continue investments in community-based and government interventions to address gynaecological morbidity, to identify how to bridge treatment-seeking gaps and to inform action at the state and national level.

\section{Abbreviations}

AYUSH: Ayurveda, Yoga \& Naturopathy, Unani, Siddha and Homoeopathy; aOR: Adjusted Odds Ratio; Cl: Confidence Interval; DLHS: District Level Household Survey; DLHS RCH: District Level Household Survey Reproductive and Child Health; HIV: Human Immunodeficiency Virus; I-WACH: India Strategy for Women's, Children's and Adolescents' Health; NFHS: National Family Health Survey; NGO: Non-Governmental Organisation; OBC: Other Backward Caste; PSU(s): Primary Sampling Units; RTI: Reproductive Tract Infection(s); SC: Scheduled Caste; SRH: Sexual and Reproductive Health; STI: Sexually Transmitted Infection(S); ST: Scheduled Tribe; UHC: Universal Health Coverage

Acknowledgements

We are grateful to Dr. Rajib Acharya, Population Council India and Dr. Devaki Nambiar, The George Institute, India, for comments on this manuscript.

\footnotetext{
Authors' contributions

AS, SB and SD conceptualized the study. SB conducted the literature review and $A S$ conducted analyses, with guidance from SD. SD reviewed results, and SD, AS and SB drafted the paper. All authors agreed on the final version. $\mathrm{SB}$ and $\mathrm{AS}$ contributed equally.
}

\section{Funding}

This paper was prepared as part of the Research \& Analysis for Scientific Transformation \& Advancement (RASTA) initiative of the Population Council and supported by the Bill and Melinda Gates Foundation, Grant \# OPP1203683. The funders had no role in data analysis, interpretation or writing of this manuscript. 


\section{Availability of data and materials}

The dataset supporting the conclusions of this article is available in the Demographic and Health Surveys (DHS) repository. The data can be downloaded from www.DHSprogram.com.

\section{Ethics approval and consent to participate}

The study conducted a secondary analysis of de-identified data available in the public domain. Further ethics approval was not required. Permission to access 2015-16 NFHS data was obtained from the DHS program, by agreeing with the conditions of data use stated in the DHS consent letter.

\section{Consent for publication}

Not Applicable.

\section{Competing interests}

The authors declare that they have no competing interests.

\section{Received: 5 August 2019 Accepted: 16 July 2020}

Published online: 28 July 2020

\section{References}

1. Germain A, Sen G, Garcia-Moreno C, Shankar M. Advancing sexual and reproductive health and rights in low-and middle-income countries: implications for the post-2015 global development agenda. Global Public Health. 2015;10(2):137-48.

2. Starrs AM, Ezeh AC, Barker G, Basu A, Bertrand JT, Blum R, et al. Accelerate progress - sexual and reproductive health and rights for all: report of the Guttmacher-lancet commission. Lancet. 2018.

3. Langer A, Meleis A, Knaul FM, Atun R, Aran M, Arreola-Ornelas H, et al. Women and health: the key for sustainable development. Lancet. 2015; 386(9999):1165-210.

4. GOI. National Health Policy. Ministry of Health and Family Welfare 2017.

5. I-WACH. India strategy for women's, adolescents' and children's health; 2018.

6. Dandona R, Pandey A, Dandona L. A review of national health surveys in India. Bull World Health Organ. 2016;94(4):286.

7. WHO. World Health Organization Sexually transmitted and other reproductive tract infections: a guide to essential practice. Geneva: World Health Organization; 2005.

8. IIPS. National Family Health Survey (NFHS-2), 1998-99. India: Institute for Population Sciences (IIPS) and Macro International; 1998.

9. IIPS. Institute for Population Sciences (IIPS) district level household Survey-3, 2007-2008. India; 2010.

10. Nagarkar A, Mhaskar P. A systematic review on the prevalence and utilization of health care services for reproductive tract infections/sexually transmitted infections: evidence from India. Indian J Sex Transm Dis AIDS. 2015;36(1):18-25.

11. Kielmann K, Bentley M. Thresholds of morbidity among women in a periurban community of Maharashtra, India: conceptual and methodological issues. J Health Psychol. 2003;8(5):525-38.

12. Koenig M, Jejeebhoy S, Singh S, Sridhar S. Investigating women's S gynaecological morbidity in India: not just another KAP survey. Reproductive health matters. 1998;6(11):84-97.

13. Oomman N. Examining determinants of Gynaecological morbidity from Women's perceptions in rural Rajasthan. Reproductive health in India: new evidence. 2008;159.

14. Prasad JH, Abraham S, Kurz KM, George V, Lalitha MK, John R, et al. Reproductive tract infections among young married women in Tamil Nadu. India Int Fam Plan Perspect. 2005;31(2):73-82.

15. Bhanderi MN, Kannan S. Untreated reproductive morbidities among ever married women of slums of Rajkot City, Gujarat: the role of class, distance, provider attitudes, and perceived quality of care. J Urban Health. 2010;87(2): 254-63.

16. Saha A, Sarkar S, Mandal N, Sardar J. Health care seeking behaviour with special reference to reproductive tract infections and sexually transmitted diseases in rural women of West Bengal. Indian J Community Med. 2006;31: 284-5.

17. Samanta A, Ghosh S, Mukherjee S. Prevalence and health-seeking behavior of reproductive tract infection/sexually transmitted infections symptomatics: a cross-sectional study of a rural community in the Hooghly district of West Bengal. Indian J Public Health. 2011;55(1):38-41.
18. Puthuchira Ravi R, Athimulam KR. Care seeking behaviour and barriers to accessing Services for Sexual Health Problems among women in rural areas of Tamilnadu state in India. J Sex Transm Dis. 2014;2014:292157.

19. Ram F. NFHS-4: an introduction. Demography India. 2014;43(1\&2):1-8.

20. ICF, IIPS. National Family Health Survey (NFHS 4). Mumbai, India: International Institute for Population Sciences; 2018.

21. Rani M, Bonu S. Rural Indian women's care-seeking behavior and choice of provider for gynecological symptoms. Stud Fam Plan. 2003;34(3):173-85.

22. Prusty RK, Unisa S. Reproductive tract infections and treatment seeking behavior among married adolescent women 15-19 years in India. International Journal of MCH and AIDS. 2013;2(1):103.

23. Anand $E$, Kumar $P$, Unisa $S$, Singh J. Neglect of menstrual disorders in reproductive health Care in India: a population-based survey. Women's Reproductive Health. 2018;5(4):287-300.

24. $\mathrm{MOH} / \mathrm{Nepal}$, New ERA/Nepal, ICF. Nepal Demographic and Health Survey 2016. Kathmandu, Nepal: Ministry of Health - MOH/Nepal, New ERA/Nepal, and ICF; 2017.

25. National Institute of Population R, Training NB, Mitra, Associates, International ICF. Bangladesh Demographic and Health Survey 2014. Dhaka, Bangladesh: NIPORT, Mitra and Associates, and ICF International; 2016.

26. Aayog N. Healthy States. Progressive India: Report on the Ranks of States and Union Territories| NITI Aayog, (National Institution for Transforming India), Government of India Available at: https://niti gov in/content/healthystatesprogressive-india-report-ranks-states-and-union-territories, 2019.

27. Verma A, Kumar Meena J, Banerjee B. A comparative study of prevalence of RTI/STI symptoms and treatment seeking behaviour among the married women in urban and rural areas of Delhi. International Journal of Reproductive Medicine. 2015;2015:563031.

28. Desai GS, Patel R. Incidence of reproductive tract infections and sexually transmitted diseases in India: levels and differentials; 2011.

29. Barua A, Kurz K. Reproductive health-seeking by married adolescent girls in Maharashtra. India Reprod Health Matters. 2001;9(17):53-62.

30. Dixon MR. Wassesheit J. International Womens Health Coalition: Culture Of Silence; 1991.

31. Santhya K. Treatment seeking for reproductive illness in rural Tamil Nadu. Reproductive health in India: new evidence. 2008;252.

32. Kostick KM, Schensul SL, Jadhav K, Singh R, Bavadekar A, Saggurti N. Treatment seeking, vaginal discharge and psychosocial distress among women in urban Mumbai. Cult Med Psychiatry. 2010;34(3):529-47.

33. Philip PS, Benjamin Al, Sengupta P. Prevalence of symptoms suggestive of reproductive tract infections/sexually transmitted infections in women in an urban area of Ludhiana. Indian Journal of Sexually Transmitted Diseases. 2013;34(2):83

34. Bhatnagar N, Khandekar J, Singh A, Saxena S. The silent epidemic of reproductive morbidity among ever married women (15-49 years) in an urban area of Delhi. J Community Health. 2013;38(2):250-6.

35. Gruskin S, Bogecho D, Ferguson L. 'Rights-based approaches' to health policies and programs: articulations, ambiguities, and assessment. J Public Health Policy. 2010;31(2):129-45.

36. Maitra K, Degraft-Johnson J, Singh KK, Tsui AO. Prevalence of self-reported symptoms of reproductive tract infections among recently pregnant women in Uttar Pradesh. India J Biosoc Sci. 2001;33(4):585-601.

37. Dawn A, Biswas R. Reproductive tract infection: an experience in rural West Bengal. Indian J Public Health. 2005;49(2):102-3.

38. Kosambiya J, Desai VK, Bhardwaj P, Chakraborty T. RTI/STI prevalence among urban and rural women of Surat: a community-based study. Indian Journal of Sexually Transmitted Diseases and AIDS. 2009;30(2):89.

39. Chatterjee CB. Identities in motion: migration and health in India: Centre for enquiry into health and allied themes Mumbai; 2006.

40. Joshi A, Dhapola M, Pelto PJ. Gynaecological problems: perceptions and treatment-seeking behaviours of rural Gujarati women. Reproductive Health in India New Evidence Jaipur: Rawat Publications. 2008:133-58.

41. Aggarwal P, Kandpal S, Negi K, Gupta P. Health seeking behaviour for RTIs/ STIs:study of a rural community in Dehradun. Health and Population Perspectives and Issues. 2009;32(2):66-72.

42. Subramanian S, Subramanyam MA, Selvaraj S, Kawachi I. Are self-reports of health and morbidities in developing countries misleading? Evidence from India. Soc Sci Med. 2009:68(2):260-5.

43. Sen A. Health: perception versus observation: self reported morbidity has severe limitations and can be extremely misleading: British Medical Journal Publishing Group; 2002. 
44. Das J, Hammer J, Sánchez-Paramo C. The impact of recall periods on reported morbidity and health seeking behavior: the World Bank; 2011.

45. IIPS. Institute for Population Sciences (IIPS) and Macro International. National Family Health Survey (NFHS-4), 2015-16, India. 2017.

46. Harlow SD, Campbell OM. Epidemiology of menstrual disorders in developing countries: a systematic review. BJOG: An International Journal of Obstetrics \& Gynaecology: REVIEW 2004;111(1):6-16.

47. Harlow SD, Campbell OM. Menstrual dysfunction: a missed opportunity for improving reproductive health in developing countries. Reproductive health matters. 2000;8(15):142-7.

\section{Publisher's Note}

Springer Nature remains neutral with regard to jurisdictional claims in published maps and institutional affiliations.

- fast, convenient online submission

- thorough peer review by experienced researchers in your field

- rapid publication on acceptance

- support for research data, including large and complex data types

- gold Open Access which fosters wider collaboration and increased citations

- maximum visibility for your research: over $100 \mathrm{M}$ website views per year

At BMC, research is always in progress.

Learn more biomedcentral.com/submissions 